\title{
Modifying Science Activities and Materials to Enhance Instruction for Students with

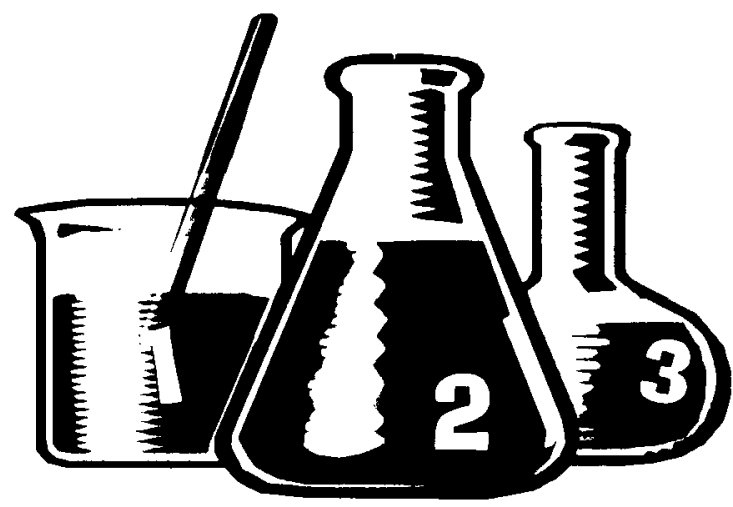 \\ Learning and Behavioral Problems
}

\author{
(IIRISIINE K. (ORMSBIE: ANI) KRVIN I). RINSON
}

\begin{abstract}
Most science educators report a willingness to teach students with learning and behavioral differences; however, they often also indicate having limited information about how to make the science classroom more accessible. One avenue of support is the modification of science instructional materials in order to reduce barriers that may exist as a result of poor reading, organization, or workcompletion skills. Some suggestions for instruction modifications are provided in this article. Also included is a sample science activity that was redesigned to support students with learning and behavioral concerns.
\end{abstract}

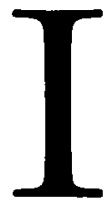

nclusion of students with disabilities in general classes is considered the best practice in toxday's schools. I This increased practice has resulted in more and more students receiving the bulk of their instruction in general education classes (Mcl cesky, Ilenry, \& Ilodges, 1998). 'The U.S. Department of Fducation reported that $35 \%$ of the 4.3 million students with disabilities in the nation's schools were mainstreamed full time while another $35 \%$ received some out-of-class instruction from special education teachers (National Science leachers Asscciation [NSTA], 1904). In a survey of elementary school teachers, science was ranked as the easiest subject in which to include students with handicaps (Atwood \& ()ldham, 1985). Two advantages teach- 
ers identified for ranking science first were its concrete hands-on activities and high levels of group interaction. These effective teaching elements seem to benefit all class members. For example, Richardson (1994) noted that general education students seemed to learn more about a subject when working with students with disabilities.

To ensure successful inclusion or mainstreaming in science, educators must use activities and laboratories that are appropriately designed for students with special needs. As designed, most standard science activities fail to accommodate for the difficulties encountered by many students with learning disabilities, behavioral disorders, and other special characteristics. Students who are not appropriately and actively engaged in learning science will likely fare poorly in science instruction (Mastropieri \& Scruggs, 1994). More specifically, learning activities that are vistally unclear or distracting, assignments that are challenging to follow, or materials that contain difficult vocabulary will increase the likelihood that students with mild-to-moderate disabilities will struggle to meet instructional objectives (Finson, Ormsbee, Jensen, \& Powers, 1997).

Science and special education faculty at a state university implemented a project addressing science activities in mainstreamed classrooms. 'Thirteen science and special educator teams in elementary and middle schools participated in the project. The groups met several times throughout the school year to participate in instruction on collaboration, effective adaptations, science literacy issues, and special education concerns. Upon completion of extensive inservice education, the teaching teams were charged with retooling science lessons and activities to support mainstreamed students with disabilities.

This project was unique in regard to the educators' approach to adapting the science instruction. First, retooling responsibilities were shared equally between science and special education teams; that is, planning, preparing, and implementing science instruction was a collaborative process. Second, retooled science activities were designed to accommodate all students, not just students with learning or behavioral concerns. The intent was not to create activities useful to only one segment of the student population but to make science instruction accessible to all students. Third, academic expectations were not lowered regarding what students could accomplish in or learn from an activity. Expectations remained high for all students. 'The retooled activities contained language, format, and organizational modifications that made them more readily usable-but not simpler-by students who had learning disabilities and behavioral disorders. All teacher team efforts focused on developing challenging and interesting learning tasks that offered structure and support to help students overcome reading, writing, or management barriers.
Preparation, lesson format, instruction, and materials were modified to ensure that learners had access to all levels of instruction. As part of the project, a list of modifications to written/printed materials was prepared along with a modified model of a science activity (see Suggested Modifications Chart on p. 12). The list was developed throughout the project by the teacher teams as they retooled science lessons and tried them with their students.

\section{A Sample Retooled Science Activity}

To illustrate how a science activity can be retooled, we have included an original and a retooled form of "the bouncing ball" in the Appendix. The "bouncing ball" activity originated with Science: $A$ Process Approach (SAPA; American Association for the Advancement of Science, 1974) but has undergone a number of teacher revisions since its publication. Hence, the "original" example we provide here may not be identical to that found in current SAPA materials. However, the example is one that has been used with students. 'This is followed by the "retooled" version, which has been reduced in size so that comments concerning specifics of the retooling could be added in the margins.

Onc obvious result of the retooling has been an increase in the number of pages required for the activity. Including the graph paper, the original activity covered three pages. The retooled version covers more. We recognize that increasing the page requirements may put an unwelcome burden on both the teacher and the school budget, but we recommend against printing on front and back to save paper since this may not be appropriate for some students with special needs. Classroom teachers have suggested providing one copy (perhaps laminated) per cooperative group of students. Single copies (nonlaminated) of the activity could be provided to students as needed on an individual basis. 'T his strategy would reduce the volume of paper consumed, as well as the time to print the activity for class use.

Students with learning disabilities and behavioral disorders can succeed in a general curriculum when appropriate modifications to instruction and materials are made. These modifications are not necessarily draining in terms of time or expense but can be made quite easily when first planning the lesson and preparing materials. Besides developing positive and satisfying professional relationships, when these instructional responsibilities are shared between general and special educators, the result is the delivery of high-quality science instruction for all students. 


\section{Suggested Modifications to Written/Printed Materials}

1. Provide typed paper materials. Do not use handwritten materials. Avoid materials written in cursive

2. Use plain lettering in printed materials. Avoid fonts with characters possessing tails (such as the tail on the " $t$ " used in this font), curly. cues, and so forth.

3. Type materials for students with type that is 10 point or larger.

4. Avoid using hyphenated words, particularly when they appear at the right margin of the page. Words that begin at the right end of one line and continue at the left margin of the next line sometimes prove difficult for students to follow.

5. Provide adequate white space to separate lines of text.

6. Provide a box or line to the left of each direction or step so students can check them off as they complete them.

7. Use photocopies rather than dittos for students since many students have difficulty reading the purple/blue print.

8. Make class sets of directions, such as one per group, rather than giving each individual student a set. You may wish to laminate the directions and keep them for reuse as permanent copies. However, you may find it necessary to provide students with disabilities their own sheets on which they can write.

9. Use graph paper with large grid spaces if possible. You may find it useful to use graph grids larger than what fits on a normal size sheet of paper. For example, large bulletin board-size grids or grids marked out on the floor may be helpful.

10. Prepare graph grids ahead of time with their axes prelabeled and marked.

11. Use colors on graphs when possible. For example, besides using different colors for graphed data, use different colors for different lines of the grid itself. The "zero" line might be black, the next line might be green, the next red, and so forth.
12. Color-code items in tasks (such as "Ball $A$," "Ball 1," etc.). Then refer to colored objects in the text of the activity.

13. Avoid using fluorescent or glossy paper.

14. Use papers of different colors for different worksheets or handouts. For example, use yellow for one worksheet, light blue for another, light green for yet another.

15. Highlight or underline verbs in directions given to students.

16. Use space to separate each step in procedures and number each step.

17. Illustrate steps in the activity with pictures or diagrams. Either include these pictures and/or diagrams in the text of the activity or provide them on large posters or overheads.

18. Provide visual cues (illustrations, drawings, demonstrations, etc.). You may desire to have students make their own drawings of things, such as laboratory apparatus.

19. Make diagrams life size when possible. Photocopy the actual item for use on handouts and worksheets. For example, if you wish to show a thermometer, use a photocopy rather than a stylized drawing of one.

20. Provide pictures or illustrations of individual steps in the activity.

21. Teach new vocabulary words at the beginning of the activity.

22. Explain to students why they are doing the activity. This may involve relating the activity to things that are done in the world outside the classroom, whether or not the student personally is likely to do them. The purpose is to tell the student that there is value in the activity's learning, and it is not simply busy work.

23. Simplify directions, making them more "step by step" in format.

24. Simplify the wording of questions that are asked of students.

25. Highlight cutting lines on papers to distinguish them from "fold" lines. 


\section{About the Authors}

Christine K. Ormsbee, PhD, is an associate professor in the Department of Educational Psychology, Special Education Programs at the University of Oklahoma. Her current research interests include determining effective modifications for students with learning and behavioral problems, identifying critical components of effective preassessment teams, and investigating the longterm effectiveness of preassessment activities on children and youth with tearning and behavioral problems. Kevin D. Finson, PhD, is a professor of science education at Western Illinois University in Macomb, IL. I His current research interests include children's perceptions of scientists and modifying science activities and assessments for use in inclusive classrooms. Address: Christine K. Ormsbee, Department of Educational Psychology, University of (Oklahoma, 820 Van Vleet Oval, Norman, ()K $7301 \%$.

\section{REFERENCES}

American Association for the Advancement of Science. (1974). Science: A process approach $1 /-T b e$ Bouncing Ball. Washington, DC. Author.

Atwood, R. K., \& Oldham, B. R. (1985). 'Teachers' perceptions of mainstreaming in an inquiry oriented elementary science program. Science Fducation, 69, 619-624.

Finson, K. D., Ormsbee, C. K., Jensen, M., \& Powers, D. T. (1997). Science in the mainstream: Retooling science activities. Fournal of Science Teacher Fducation, 8(3), 219-232.

Mastropieri, M. A., \& Scruggs, T. E. (1994). Text versus hands-on science curriculum: Implications for students with disabilities. Remedial and Special Education, 15(2), 72-85.

McI eskey, J., I Ienry, D., \& I lodges, D. (1998). Inclusion: Where is it happening? Teaching Faccptional Children, $31(1),+-10$.

National Science 'leachers Association. (1994, May/Junc). NSTA Report (Newspaper). Washington, DC: Author. (Available from NSIA, 1840) Wilson Blvd., Arlington, VA 22201-300(0)

Richardson, M. (1994). Wc all learned together. Science Scope, 17(6), 68-70.

(Appendix A: The Original Bouncing Ball begins next page)

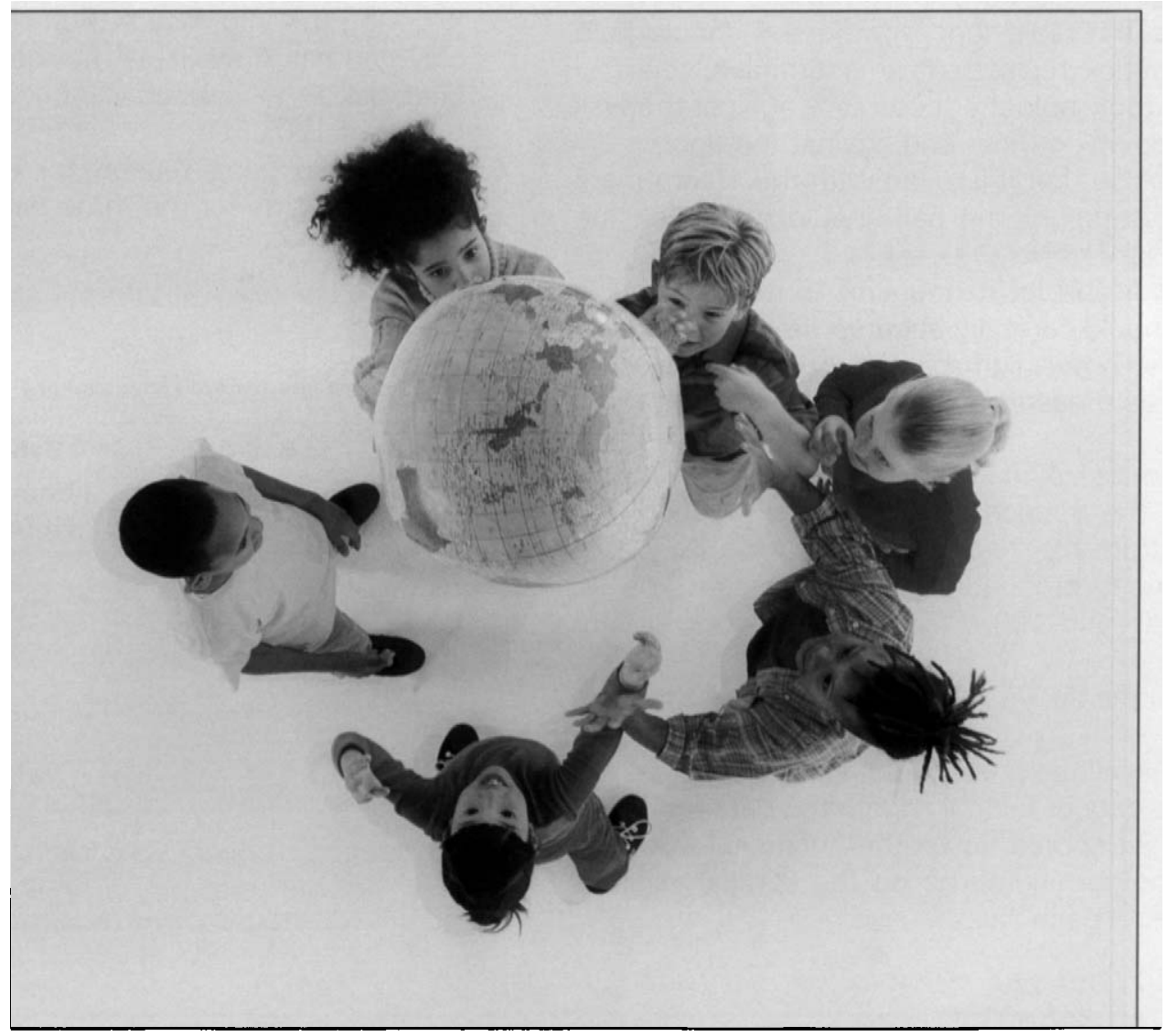




\section{Appendix A: The Original Bouncing Ball}

\section{Objectheas}

After completing this activity, the student should be able to ...

1. construct a graph with two variables and

2. predict future outcomes based on interpretations of graphed data.

\section{Materials:}

1 roll masking tape, 3 rubber balls ( 3 different types), 3 colored pencils, 1 meterstick, 1 sheet graph paper. 1 pencil

\section{Procedures:}

A. Take rubber ball $A$ and the meterstick. Stand the meterstick upright on the table (or floor) so that the $0-\mathrm{cm}$ end is against the table top (or floor). The meterstick should be at a right angle (or perpendicular) to the table top. One person should hold the meterstick in place. As an alternative, you may wish to simply hold the meterstick against the wall while keepıng its $0-\mathrm{cm}$ end against the floor.

B. Hold ball A so that it is even with the $10-\mathrm{cm}$ mark of the meterstick. The ball should not touch the meterstick.

C. Drop ball $A$ and let it bounce. As this is done, a partner should carefully observe the ball and try to determine how high ball $A$ bounces (in $\mathrm{cm}$ ). Record this measurement as "bounce height" on Table A.

D. Now hold ball $A$ at the $20-\mathrm{cm}$ level and drop it. Measure the bounce height for ball $A$ when it is dropped from the 20-cm level.

E. Repeat these procedures for drop heights of 30 , $40,50,80$, and $100 \mathrm{~cm}$. Be sure to record your data on Table $A$.

F. Repeat all the above procedures, but this time use ball $B$.

$G$. Now repeat all the procedures again, but use ball $C$.

$H$. Using the data in Table A, graph the data for ball $A$. Drop height should be on the horizontal axis, and bounce height should be on the vertical axis. Be sure to label each axis.
I. Graph the data for balls B and C. Use different colors or different types of lines for each ball (so you can tell them apart from each other and apert from the line for ball $A$ ).

\section{Questions:}

1. Using the graph you constructed, predict the height that ball $A$ would bounce if it was dropped from a height of $75 \mathrm{~cm}$.

2. How high do you think ball $A$ would bounce if you dropped it from a height of $120 \mathrm{~cm}$ ? Explain why you think this.

3. Did all three balls bounce the same amounts (did each have the same bounce height for a given drop height)?

4. What is the average difference $(\mathrm{In} \mathrm{cm})$ of bounce height of ball $B$ compared to ball $A$; of ball $C$ compared to ball $A$; of ball $B$ compared to ball $C$ ?

5. Knowing the information from question \#4, if you only had ball $A$ available, how high would you expect ball $C$ to bounce if you dropped it from a height of $120 \mathrm{~cm}$ ?

6. What could be a reason for any differences in bounce heights for the three balls?

Tablo A. Drop and Botence Height Record

\begin{tabular}{llll}
\hline $\begin{array}{c}\text { Drop } \\
\text { Ht (cm) }\end{array}$ & $\begin{array}{c}\text { Ball A } \\
\text { Bounce } \\
\text { Ht }(\mathbf{c m})\end{array}$ & $\begin{array}{c}\text { Ball B } \\
\text { Bounce } \\
\text { Ht (cm) }\end{array}$ & $\begin{array}{c}\text { Ball C } \\
\text { Bounce } \\
\text { Ht (cm) }\end{array}$ \\
\hline 10 & & & \\
\hline 20 & & & \\
\hline 30 & & \\
\hline 40 & & \\
\hline 50 & & \\
\hline 80 & & \\
\hline 100 & & \\
\hline
\end{tabular}




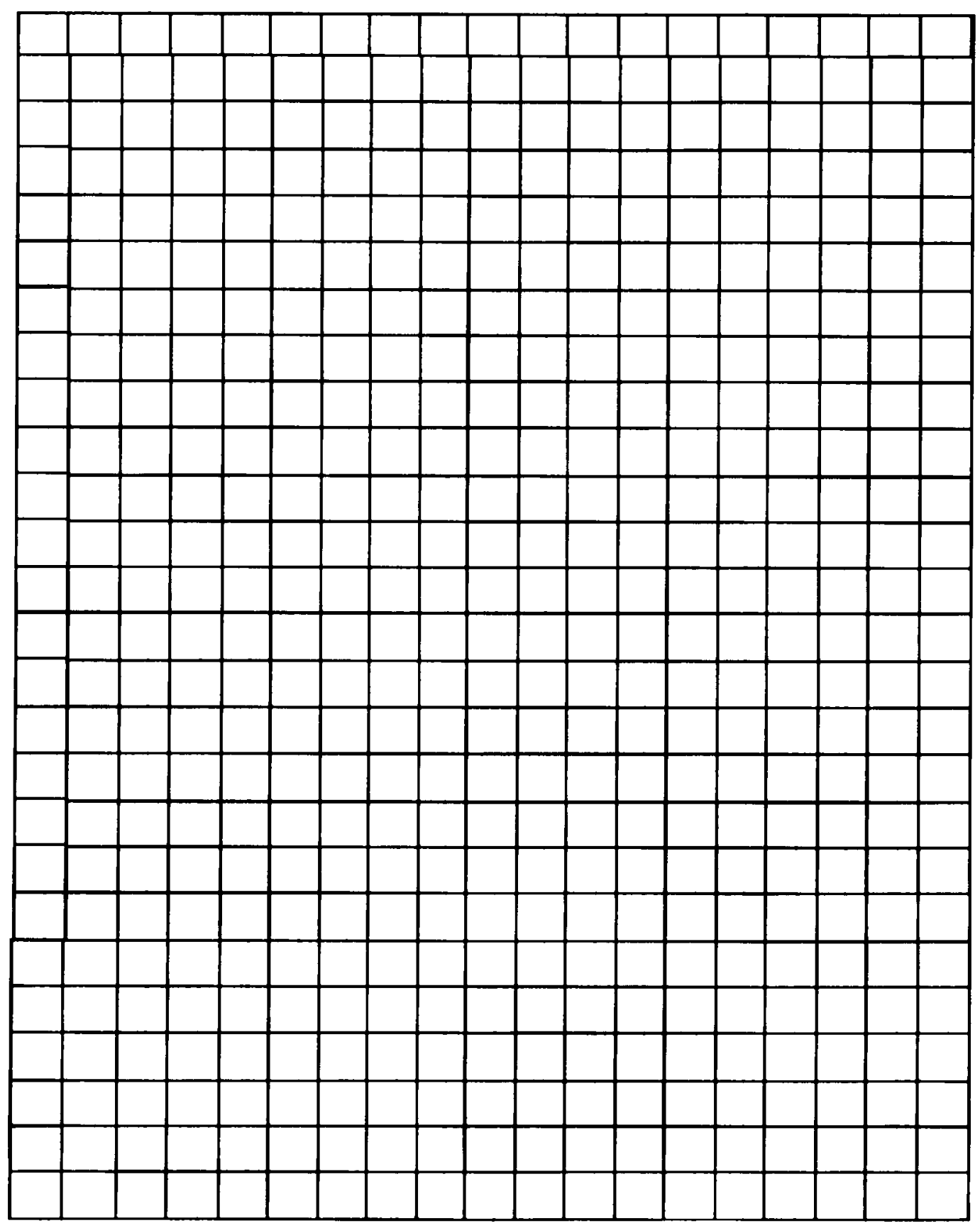

Graph that may be used to chart data. 


\section{Appendix B: Modified Bouncing Ball}

Bnilenale:

THE BOUNCING BALL

Imagine that one day you went into an electronics store to purchase a VCA. In the store, you can find Brand $A$ and Brand B, but not Brand $\mathbf{C}$. From what you've read, you know that Brand $C$ is very similar to Brand $A$, but you have not actually seen Brand $A$ before. You take a videotape and place it first in Brand $A$ and later in Brand $B$ so that you can compare how the two VCAs operate. From this information, you may be able to infer how Brand $C$ will also operate. Then you can make a decision about which VCA you will probably purchase.

In the situation described in the above paragraph, you collected data about one or two objects and applied that information to find out information about other objects. You may be faced with simllar situations at different times in your life. In this activity, you will do a similar thing, but you will be collecting data about different balls. You will be analyzing the data, and making some decisions based on your data.

\section{Vocabulary:}

axis

graph

centimeter

height

$\mathrm{cm}$

horizontal

bounce height

horizontal axis

drop height

meterstick
This section on "Rationale" was added so that students could see some reason for doing the activity and better understand how the activily relates to the world around them.

The font of the lettering was changed so as to avoid having letters with tails (such as at the bottom of " $t$ ") or curley-cues, which prove problematic for some students in their reading.

Vocabulary words which arise in this activity were added. Although some students may not need the help of having these words highlighted, others may benefit by learning them prior to doing the activity.

\section{Oblectives:}

After completing this activity, the student should be able to . .

1. collect and record data from an experiment,

2. construct a graph with two variables, and

Verbs in the directions given to students have been highlighted to help

3. predict future outcomes based on interpretations of graphed data. guide students.

\section{Materials:}

1 Roll Masking Tape

3 Rubber Balls (red, green, blue)

3 Colored Pencils (red, green, blue)
1 Pencil

1 Meterstick

1 Sheet Graph Paper

- Although the sample shown here is reduced in size, the print size used on the page is no smaller than 12 point.

- Efforts have been made to provide more white space to avoid cluttered appearances. Margins on all sides have not been reduced.

- The activity is photocopied and not reproduced on ditto or mimeograph, both of which sometimes prove difficult for students to read.

- Directions have been simplified. Shorter, more direct wording is used. 


\section{THE BOUNCING BALL}

\section{Procedures:}

Step A:

1. Get the RED BALL and the meterstick.

2. Stand the meterstick upright on the table (or floor) so that the $0-\mathrm{cm}$ end is against the table top (or floor).

3. The meterstick should be at a right angle (or perpendicular) to the table top.

4. One partner should hold the meterstick in place.

5. As an alternative, you may wish to simply hold the meterstick against the wall while keeping its $0-\mathrm{cm}$ end against the floor.

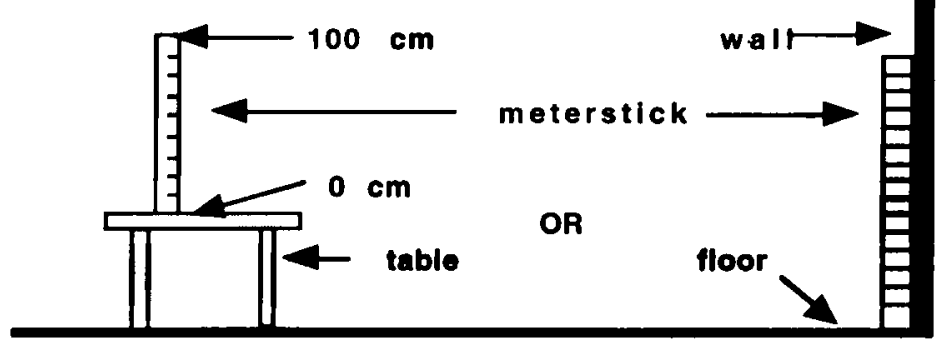

\section{Step B:}

1. Hold the RED BALL so that it is even with the $10-\mathrm{cm}$ mark of the meterstick.

2. The ball should not touch the meterstick.

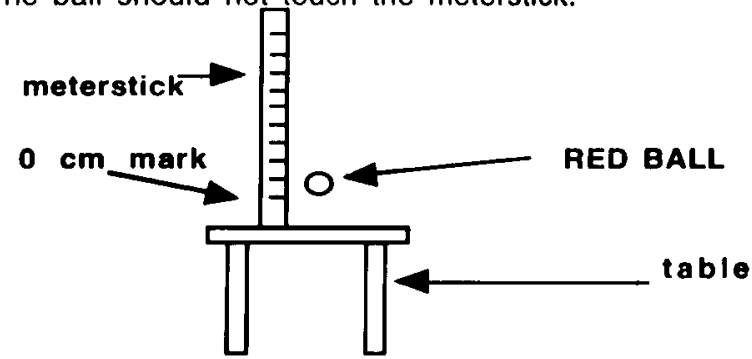

Page 2

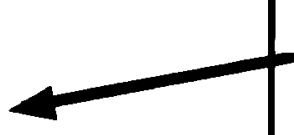$$
\text { Bla }
$$

Blank lines have been added at the left margin of the activity's various steps. Students can check off steps as they complete them.

Diagrams have been added to illustrate for students what is being described in the text of the activity. Although not "life sized," these diagrams should help students better understand how to set up the equipment and use it.

So the various steps of the activity will stand out, they have been separated by dotted lines. Students can more easily identify one set of procedures from another.

The diagram shows that the bottom of the red ball should be at the $10 \mathrm{~cm}$ mark, from where it is to be dropped.

- The metersticks used should be color coded by decimeters. For example, the first decimeter may be lined with a thin strip of yellow tape. The second decimeter may be lined on the edge with a thin strip of red tape. Other decimeters are color coded in similar ways. This aids students in spotting the balls' bounce heights more effectively. 


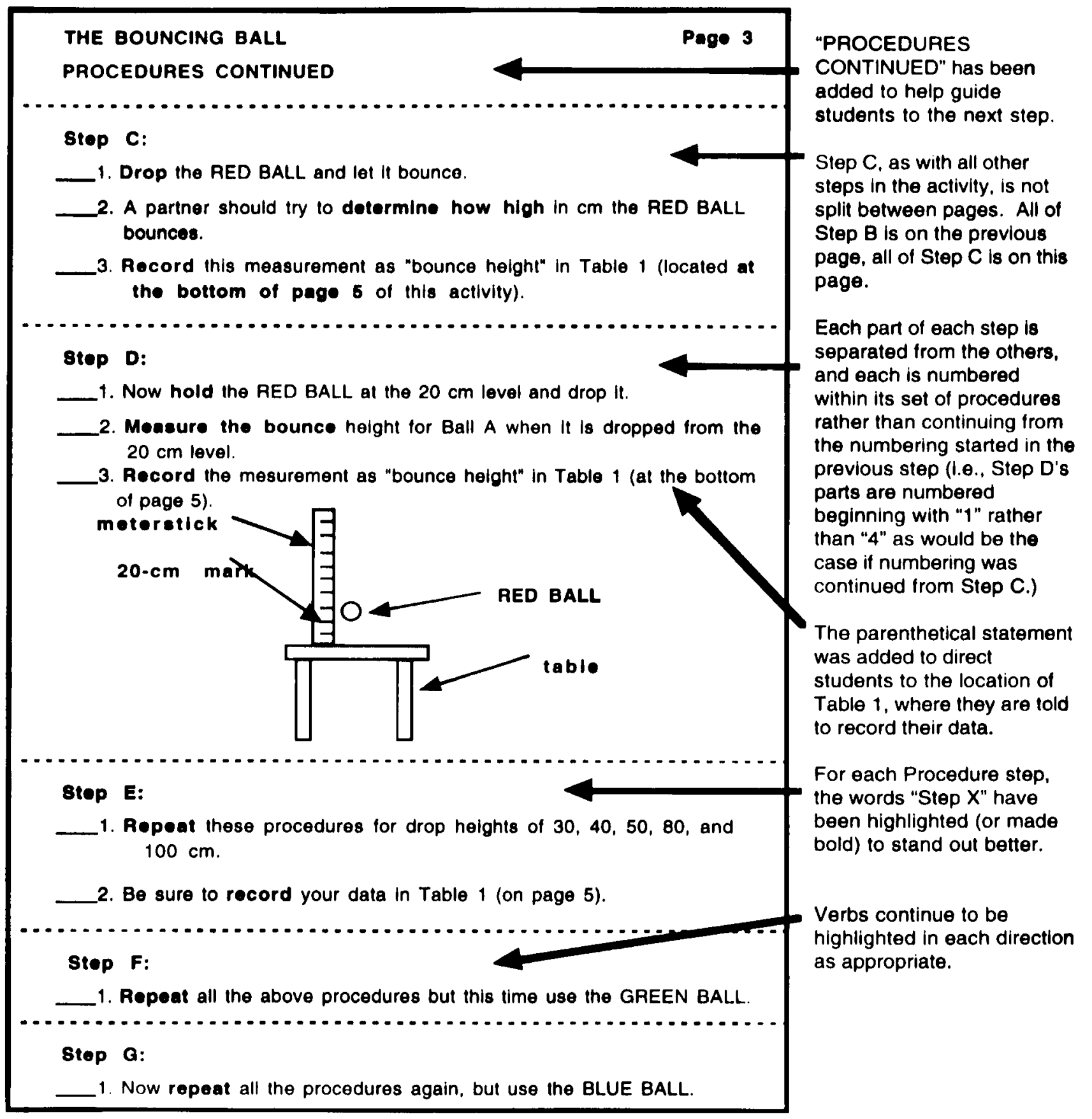




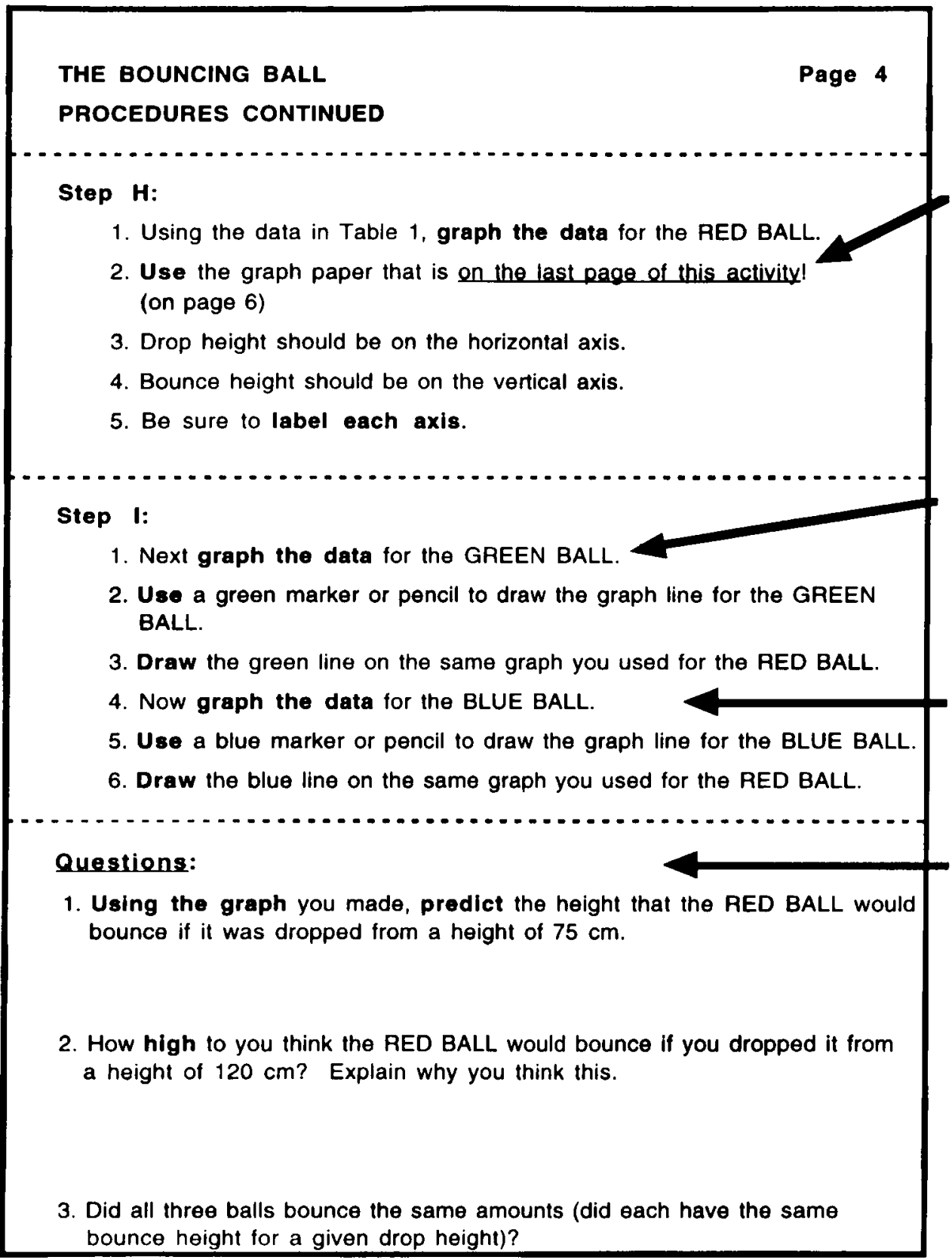

The students are told exactly where to find the graph paper they are to use for the data they record in Table 1 (on page 5).

Ball \#2 has been renamed GREEN BALL. The actual ball used should be green.

Ball \#3 has been renamed BLUE BALL, and the ball should be blue.

As with the Procedures sections and steps, the Questions section is separated from the others. Each question is provided ample white space and room for student answers. Verbs are highlighted where appropriate. 


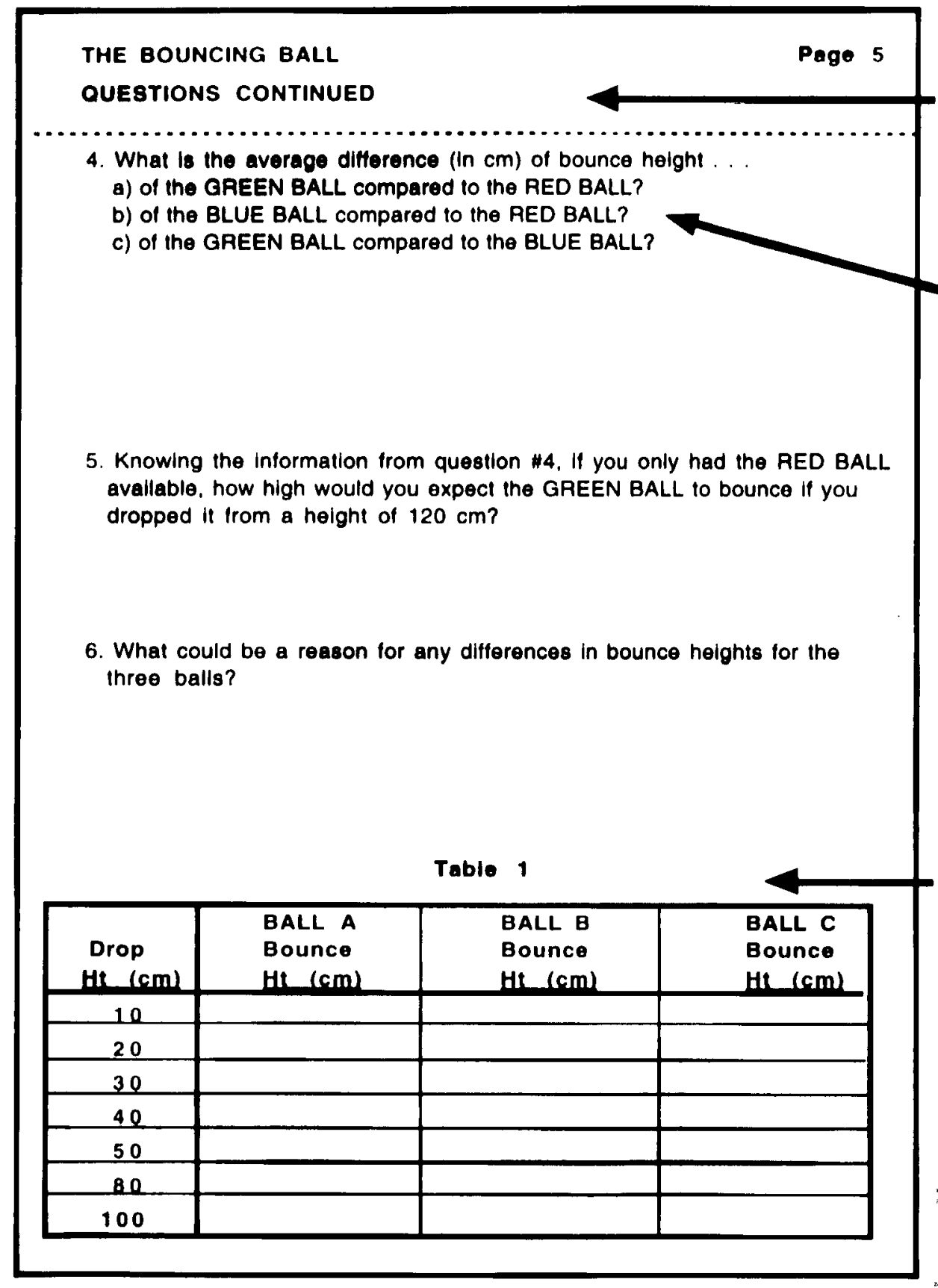

Students are informed that the Question section continues onto this page by the highlighted header.

Ball names (RED BALL, GREEN BALL, BLUE BALL) are put in capital letters to help students more easily identify the things of focus in the question.
The table in which students are to record data is placed by itself and exactly where students are told it would be when reading Procedure Step D, part 3. The table is also not embedded in the text of the activity on page 3 , where students will have to constantly flip pages back and forth to find it. 


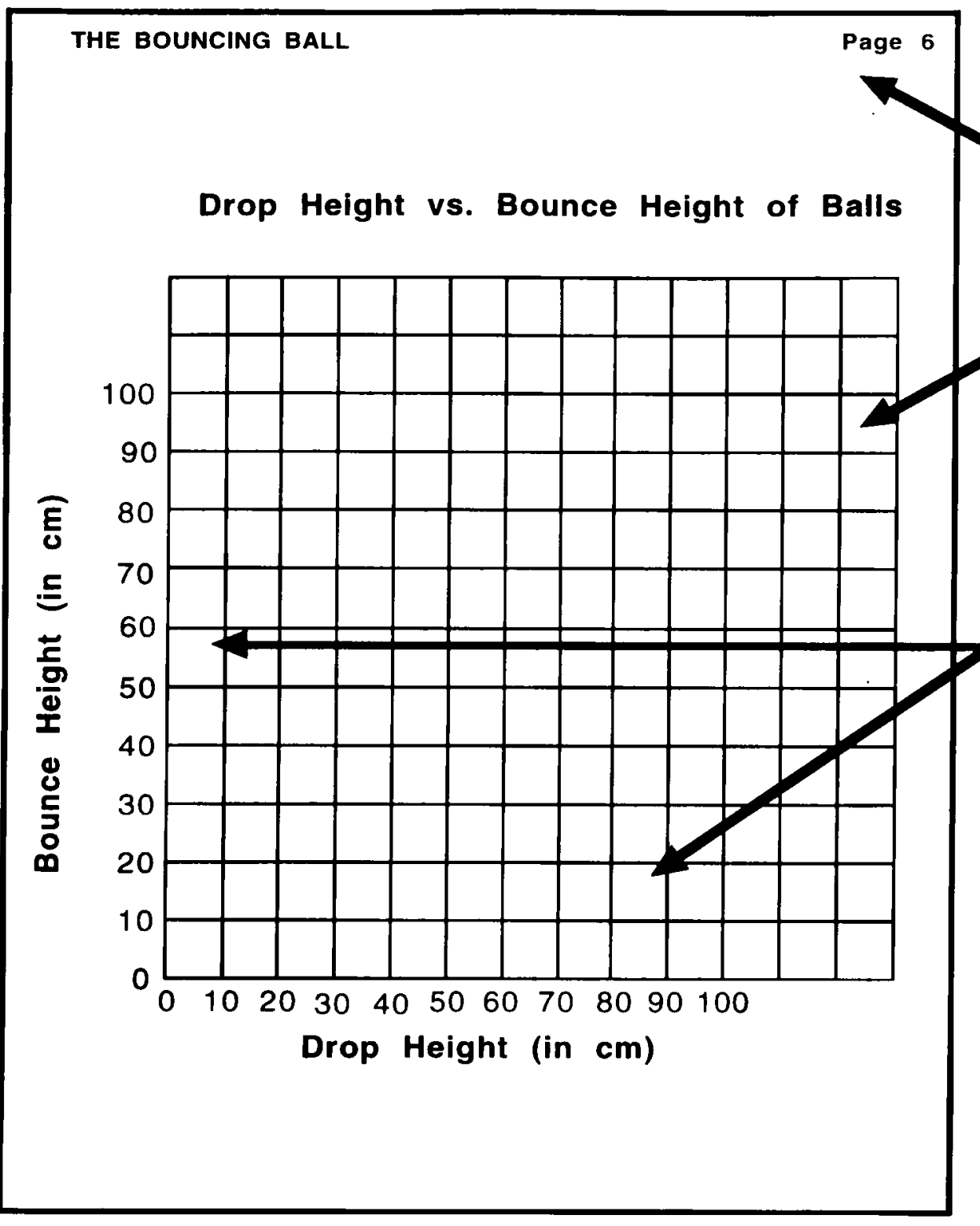

The graph is located on the last page, exactly where students were told it would be located (on page 4 . beginning in Step $\mathrm{H}$ ).

The graph paper grid is larger than normal but still fits within the range of data likely to be collected by students (and still able to fit on a single page).

The graph grid's axes were prepared ahead of time and labeled for the student. Similarly, scale units have been pre-marked for students.

Students should use colored markers (pencils. pens, etc.) for their graphs. Red markers should be used for RED BALL data, green markers for GREEN BALL data, and blue markers for BLUE BALL. data. Other data can be made with a black marker, or other colors as desired or needed. 